\title{
Personality patterns and Smoking behavior among students in Tabriz, Iran
}

\section{Ali Fakharri ${ }^{1}$, Ali Jahani ${ }^{1}$, Homayoun Sadeghi-Bazargani ${ }^{2}$, Mostafa Farahbakhsh ${ }^{3}$, Asghar Mohammadpour Asl ${ }^{4}$}

${ }^{1}$ Research Center of Psychiatry and Behavioral Sciences, Tabriz University of Medical Sciences, Tabriz, Iran

${ }^{2}$ Road Traffic Injury Research Center, Department of Statistics \& Epidemiology, Tabriz University of Medical Sciences, Tabriz, Iran

${ }^{3}$ Tabriz Health Services Management Research Center, Tabriz University of Medical Sciences, Tabriz, Iran

${ }^{4}$ Department of Epidemiology \& Statistics, Tabriz University of Medical Sciences, Tabriz, Iran

\section{Type of article: Original}

\begin{abstract}
Introduction: Psychological factors have always been considered for their role on risk taking behavior such as substance abuse, risky driving and smoking. The aim of this study was to determine the association between smoking behavior and potential personality patterns among high school students in Tabriz, Iran.

Methods: Through a multistage sampling in a cross-sectional study, 1000 students were enrolled to represent the final grade high school student population of Tabriz, Iran in 2013. The personality patterns along with smoking status and some background information were collected through standard questionnaires along with Millon Clinical Multiaxial Inventory-III (MCMI-III). Fourteen personality patterns and ten clinical syndromes. ANOVA and Kruskal Wallis tests were used to compare numeric scales among the study participants, with respect to their smoking status. Stata version 13 statistical software package was used to analyze the data. Multivariate logistic regression was used to predict likelihood of smoking by personality status.

Results: Two logistic models were developed in both of whom male sex was identified as a determinant of regular smoking $\left(1^{\text {st }}\right.$ model $)$ and ever-smoking $\left(2^{\text {nd }}\right.$ model $)$. Depressive personality increased the likelihood of being a regular smoker by 2.8 times $(\mathrm{OR}=2.8,95 \% \mathrm{CI}: 1.3-6.1)$. The second personality disorder included in the model was sadistic personality with an odds ratio of 7.9 (96\% CI: $1.2-53 \%)$. Histrionic personality increased the likelihood of experiencing smoking by 2.2 times $(\mathrm{OR}=2.2,95 \% \mathrm{CI}$ : 1.6-3.1) followed by borderline personality $(\mathrm{OR}=2.8,95 \%$ CI: 0.97-8.1).

Conclusion: Histrionic and depressive personalities could be considered as strong associates of smoking, followed by borderline and sadistic personalities. A causal relationship couldn't be assumed unless well controlled longitudinal studies reached the same findings using psychiatric interviews.

Keywords: Smoking; Personality; Students; MCMI-III
\end{abstract}

\section{Introduction}

Smoking as an important risk factor of non-communicable diseases is a major public health problem both in high income countries and other low or middle income countries. About five million premature deaths worldwide throughout the year 2000 were attributable to smoking, with nearly half of them occurring in developing countries (1). Smoking with $4.1 \%$ DALY is reported to be among the leading causes of global burden of diseases (2). It is crucial to implement effective national programs in order to reduce this burden especially in developing countries (3). In spite of the current substantial knowledge on the risks of smoking it continues to preserve high rates worldwide. Therefore, it seems plausible to investigate smoking as a risky behavior. Psychological factors have always been considered for their role on risk taking behaviors such as substance abuse, risky driving and smoking (4-7). Personality patterns could be considered as a psychological background for human behavior. Research on the prevalence of personality disorders in smokers has raised many discrepancies, leading to highly variant prevalence of these disorders among cigarette smokers. Contrary to the associations between AXIS II psychiatric disorders,

\section{Corresponding author:}

Homayoun Sadeghi-Bazargani, Department of Statistics \& Epidemiology, Tabriz University of Medical Sciences, Tabriz, Iran. Tel: +98.9144027218, Email: homayoun.sadeghi@gmail.com

Received: July 29, 2016, Accepted: December 24, 2016, Published: March 2017

iThenticate screening: October 27, 2016, English editing: January 14, 2017, Quality control: February 20, 2017

(C) 2017 The Authors. This is an open access article under the terms of the Creative Commons Attribution-NonCommercialNoDerivs License, which permits use and distribution in any medium, provided the original work is properly cited, the use is non-commercial and no modifications or adaptations are made. 
such an association of personality patterns with smoking, especially investigated at student populations, are scarce. Defining the personality patterns could be of help also, in improving the knowledge on predictors of smoking cessation in order to implement smoking control programs (8-11). Regardless of the substantial number of papers published globally (12-16), very few studies have focused on assessing personality patterns and smoking in Iran, and this seems to be the first study from East Azerbaijan province of Iran. The aim of this study was to determine the association between smoking behavior and potential personality patterns among high school students in Tabriz, Iran.

\section{Material and Methods}

\subsection{Research design and participants}

A cross-sectional study design was applied to study the personality patterns among high school students and its association with smoking. Study was conducted in Tabriz in north-west Iran. Final grade high school and preacademic college students of both genders comprised the study population. According to the types of school in Iran, the targeted schools of Tabriz city in each region (both genders) were categorized into public schools, private schools, technical and vocational training schools, and work-Knowledge schools. Through a multistage sampling, 1000 students were enrolled to represent the final grade high school student population of Tabriz to identify a minimum proportion of 0.1 , and 0.2 relative difference assuming a maximum of 0.05 type I error with a predicted $12 \%$ attrition for common personality patterns among the smokers.

\subsection{Instruments}

The personality patterns along with smoking status and some background information were collected through standard questionnaires. In present study, the cigarette smoking status was measured using a valid algorithm. To consider the factors relating to cigarette smoking, the respondents were classified according to Kaplan et al. in three stages of cigarette smoking continuum as: 1) Never Smoker: adolescents who have never smoked (even a puff); 2) Experimenter: adolescents who have tried a cigarette (even a puff), but have smoked less than 100 cigarettes in their lifetime; 3) Regular smoker: adolescents who have smoked 100 cigarettes or more in a lifetime, without considering their present consumption. Personality patterns were assessed using the Millon Clinical Multiaxial Inventory-III (MCMI-III) (17). Persian version of the inventory which was earlier validated was administered (18). MCMI-III is a 175-item self-report scale with a dichotomous true-false response options. The inventory assesses 14 personality patterns and 10 clinical syndromes. The personality patterns assessed included; schizoid, avoidant, depressive, dependent, histrionic, narcissistic, antisocial, sadistic, compulsive, negativistic, masochistic, schizotypal, borderline, and paranoid. The 10 clinical syndromes included anxiety, somatoform, bipolar: manic, dysthymia, alcohol dependence, drug dependence, post-traumatic stress, thought disorder, major depression and delusional disorder. Raw scores were converted into prevalence scores and treated as a continuous scale to be compared among the three groups of study participants according to their status on smoking.

\subsection{Statistical analysis}

Numeric scores of the 14 personality patterns and 10 clinical syndromes were compared among smoking stage groups using one-way analysis of variance or Kruskal Wallis tests considering the distribution of values. Numeric scores were dichotomized using a cutoff of 75 and binary variables were created. Multivariate logistic regression analysis was used to determine predictors of either regular smoking or ever-smoking through two separate models. A p-value below 0.05 was considered statistically significant.

\subsection{Ethics of research}

The respondents were ensured about the voluntary nature of participating in the study and confidentiality of the information prior to the questionnaire; also, they were asked not to enter their personal information in the questionnaire. This study and the relating questionnaire have been approved by the East Azerbaijan Province Education Organization and Ethics Committee of Tabriz University of Medical Sciences.

\section{Results}

Two-third of the participants studied in any of the three popular majors called 'social science', 'natural science' and 'mathematical science' comprised $18.8 \%, 19.8 \%$ and $23.9 \%$ of the students respectively. The remainder $(28.1 \%)$ studied in other fields such as 'accounting' and technical fields such as electronics, computers, mechanics and other similar fields. $460(46 \%)$ of the participants were boys and $540(54 \%)$ were girls. $78.1 \%$ of students stated that they had never smoked, $4.3 \%$ stated to be regular smokers and $17.6 \%$ were classified as experimenters. The smoking status was associated with gender, such that about $70 \%$ of the boys versus $85 \%$ of the girls had never smoked and 40 $(9.2 \%)$ boys were regular smokers compared with just 1 girl out of the girl population $(0.2 \%)$ who stated to be 
regular smokers $(\mathrm{P}<0.001)$. Comparing the dichotomized scores over 75 , the histrionic, depressive and narcissistic personality patterns were respectively the most common personality patterns both among the girls and boys. Distribution of MCMI-III scores for the 14 personality patterns and the 10 clinical syndromes are compared in Figure 1. The highest three mean scores in the never smoker group were compulsive, histrionic, and narcissistic disorder fields respectively. The highest three mean scores in the experimenter group were histrionic, narcissistic and compulsive disorder fields respectively. The highest three mean scores in the regular smoker group were histrionic, depressive and thought disorder fields respectively. Mean scores for the histrionic personality were 62.2, 60 and 52.2 respectively for regular smokers, experimenters and nonsmokers. Mean scores for all personality fields are compared among the groups in Table 1.

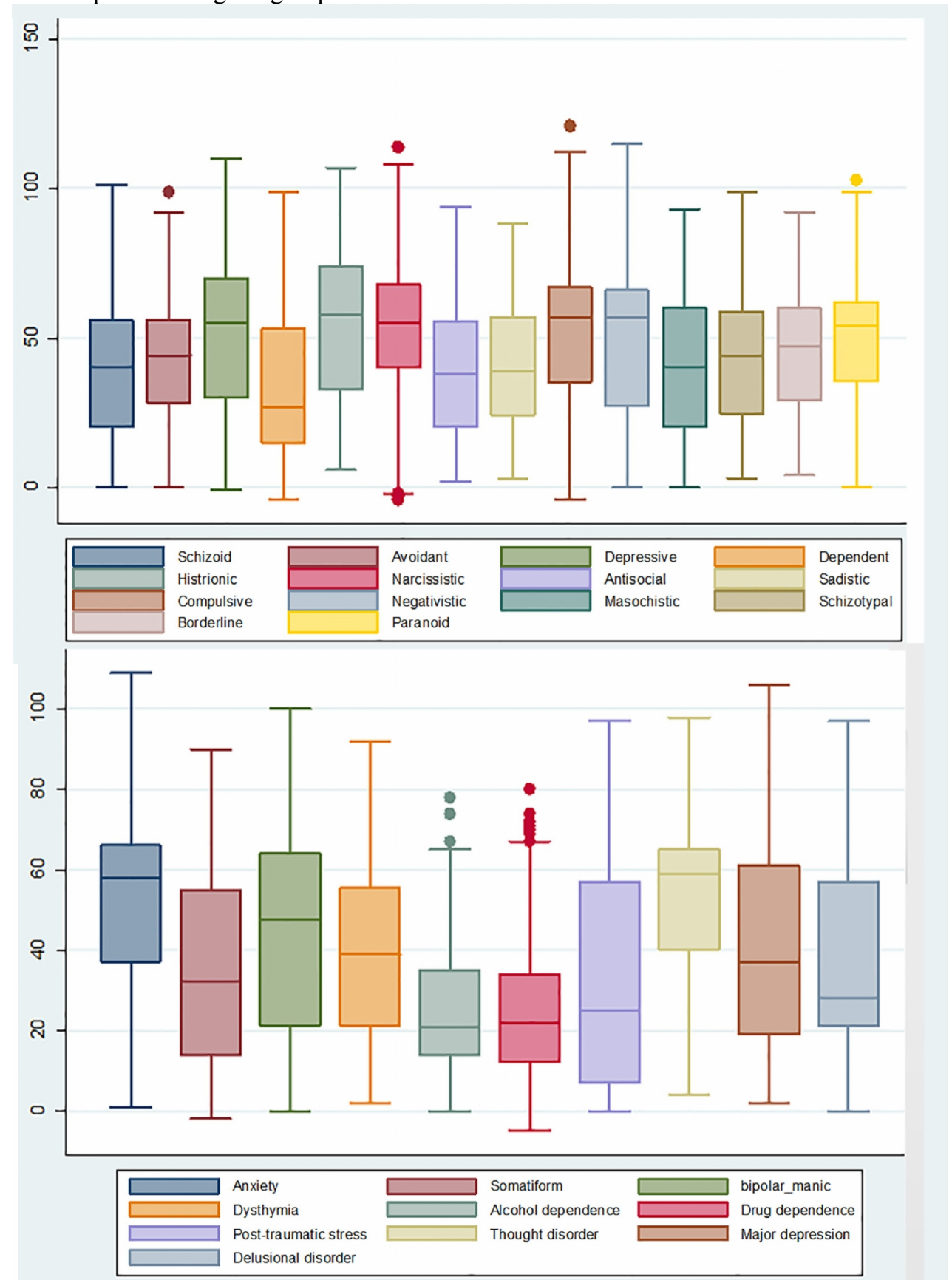

Figure 1. Distribution of MCMI-III scores compared for the 14 personality patterns and 10 clinical syndromes among a high school student population. The lower and upper box sides represent the first and third quartiles of scores. The transverse line within the box represents median MCMI-III scores. The T skewers represent the upper and lower limits excluding the outliers which are marked with dots here above or below the boxes. 
Table 1. Mean scores for all MCMI-III personality fields compared among the groups according to the smoking status

\begin{tabular}{|c|c|c|c|c|c|c|c|c|}
\hline \multirow{2}{*}{\multicolumn{2}{|c|}{$\begin{array}{l}\text { MCMI-III personality patterns \& } \\
\text { clinical symptoms }\end{array}$}} & \multicolumn{2}{|c|}{ Never smoker } & \multicolumn{2}{|c|}{ Experimenter } & \multicolumn{2}{|c|}{ Regular smoker } & \multirow{3}{*}{$\begin{array}{l}\text { p-value } \\
\text { ANOVA } \\
0.47\end{array}$} \\
\hline & & \multirow{2}{*}{$\begin{array}{l}\begin{array}{l}\text { Mean } \\
(\mathrm{SD})\end{array} \\
38.3 \\
(20.4)\end{array}$} & \multirow{2}{*}{$\begin{array}{l}\begin{array}{l}\text { Median } \\
\text { (IQR) }\end{array} \\
40(36)\end{array}$} & \multirow{2}{*}{$\begin{array}{l}\text { Mean } \\
\text { (SD) } \\
40 \\
(19.9)\end{array}$} & \multirow{2}{*}{$\begin{array}{l}\begin{array}{l}\text { Median } \\
(\mathrm{IQR})\end{array} \\
46(38)\end{array}$} & \multirow{2}{*}{$\begin{array}{l}\begin{array}{l}\text { Mean } \\
(\mathrm{SD})\end{array} \\
41 \\
(19.6)\end{array}$} & \multirow{2}{*}{$\begin{array}{l}\begin{array}{l}\text { Median } \\
\text { (IQR) }\end{array} \\
47(40)\end{array}$} & \\
\hline $\begin{array}{l}\text { Clinical } \\
\text { personality }\end{array}$ & Schizoid & & & & & & & \\
\hline patterns & Avoidant & $\begin{array}{l}40.6 \\
(19.4)\end{array}$ & $44(33)$ & $\begin{array}{l}41.3 \\
(20.1)\end{array}$ & $44(26)$ & $\begin{array}{l}45.6 \\
(16.9)\end{array}$ & $48(25)$ & 0.27 \\
\hline & Depressive & $\begin{array}{l}50.2 \\
(25.7)\end{array}$ & $53(38)$ & $\begin{array}{l}54.4 \\
(23.5)\end{array}$ & $55(31)$ & $\begin{array}{l}61.1 \\
(22.9)\end{array}$ & $64(27)$ & $<0.01$ \\
\hline & Dependent & $\begin{array}{l}33.8 \\
(22.9)\end{array}$ & $27(35)$ & $\begin{array}{l}36.3 \\
(23.8)\end{array}$ & $33(45)$ & $\begin{array}{l}31.6 \\
(18.4)\end{array}$ & $27(20)$ & 0.34 \\
\hline & Histrionic & $\begin{array}{l}52.2 \\
(23.8)\end{array}$ & $56(40)$ & $\begin{array}{l}60 \\
(25.3)\end{array}$ & $65(40)$ & $\begin{array}{l}62.2 \\
(20.3)\end{array}$ & $64(31)$ & $<0.001$ \\
\hline & Narcissistic & $\begin{array}{l}52.1 \\
(20.6)\end{array}$ & $54(29)$ & $\begin{array}{l}55.7 \\
(21.4)\end{array}$ & $60(32)$ & $\begin{array}{l}53.9 \\
(19.6)\end{array}$ & $57(27)$ & 0.12 \\
\hline & Antisocial & $\begin{array}{l}36.3 \\
(18.8)\end{array}$ & $31(33)$ & $\begin{array}{l}43.5 \\
(18.6) \\
\end{array}$ & $47(32)$ & $\begin{array}{l}51.1 \\
(17)\end{array}$ & $58(13)$ & $<001$ \\
\hline & Sadistic & $\begin{array}{l}39.1 \\
(18.6)\end{array}$ & $36(32)$ & $\begin{array}{l}42.6 \\
(18.4)\end{array}$ & $40(32)$ & $\begin{array}{l}50.3 \\
(16.1)\end{array}$ & $53(26)$ & $<0.001$ \\
\hline & Compulsive & $\begin{array}{l}53.2 \\
(21.7) \\
\end{array}$ & $60(32)$ & $\begin{array}{l}45.1 \\
(21.7)\end{array}$ & $42(37)$ & $\begin{array}{l}47.7 \\
(21.8)\end{array}$ & $51(39)$ & $<0.01$ \\
\hline & Negativistic & $\begin{array}{l}47.7 \\
(23.2)\end{array}$ & $54(39)$ & $\begin{array}{l}53.1 \\
(20.6)\end{array}$ & $59(26)$ & $\begin{array}{l}54.9 \\
(19)\end{array}$ & $60(27)$ & 0.058 \\
\hline & Masochistic & $\begin{array}{l}39.1 \\
(21.1)\end{array}$ & $40(39)$ & $\begin{array}{l}42 \\
(20.6)\end{array}$ & $43(42)$ & $\begin{array}{l}45.5 \\
(18.4)\end{array}$ & $50(30)$ & 0.14 \\
\hline \multirow[t]{3}{*}{$\begin{array}{l}\text { Severe personality } \\
\text { pathology }\end{array}$} & Schizotypal & $\begin{array}{l}40.8 \\
(19.8)\end{array}$ & $42(35)$ & $\begin{array}{l}45.6 \\
(17.9)\end{array}$ & $48(27)$ & $\begin{array}{l}48.5 \\
(17.4)\end{array}$ & $47(27)$ & 0.0011 \\
\hline & Borderline & $\begin{array}{l}43.4 \\
(18.9)\end{array}$ & $46(31)$ & $\begin{array}{l}47.3 \\
(18.4)\end{array}$ & $51(26)$ & $\begin{array}{l}47.7 \\
(16.3)\end{array}$ & $51(24)$ & 0.0455 \\
\hline & Paranoid & $\begin{array}{l}48.2 \\
(17.5)\end{array}$ & $50(27)$ & $\begin{array}{l}50.1 \\
(17.1)\end{array}$ & $55(23)$ & $\begin{array}{l}54.6 \\
(15.4)\end{array}$ & $57(21)$ & 0.0209 \\
\hline \multirow[t]{7}{*}{$\begin{array}{l}\text { Clinical } \\
\text { syndromes }\end{array}$} & Anxiety & $\begin{array}{l}50.1 \\
(21.1)\end{array}$ & $57.5(30)$ & $\begin{array}{l}49.2 \\
(20.8)\end{array}$ & $58(28)$ & $\begin{array}{l}54.2 \\
(17.8)\end{array}$ & $59(22)$ & 0.4 \\
\hline & Somatiform & $\begin{array}{l}33.6 \\
(21)\end{array}$ & $31(39)$ & $\begin{array}{l}39.4 \\
(21.4)\end{array}$ & $47(39)$ & $\begin{array}{l}41.2 \\
(20.1)\end{array}$ & $45(29)$ & $<0.001$ \\
\hline & bipolar: manic & $\begin{array}{l}40.8 \\
(25.1)\end{array}$ & $46(42)$ & $\begin{array}{l}44.3 \\
(23.1)\end{array}$ & $48(40)$ & $\begin{array}{l}45.4 \\
(21.5)\end{array}$ & $51(34)$ & 0.14 \\
\hline & Dysthymia & $\begin{array}{l}37.8 \\
(20.1) \\
\end{array}$ & $37(35)$ & $\begin{array}{l}41.6 \\
(19.1)\end{array}$ & $44(33)$ & $\begin{array}{l}45.3 \\
(18.8)\end{array}$ & $48(22)$ & $<0.01$ \\
\hline & $\begin{array}{l}\text { alcohol } \\
\text { dependence }\end{array}$ & $25(17)$ & $21(21)$ & $\begin{array}{l}29.8 \\
(17.1) \\
\end{array}$ & $28(34)$ & $\begin{array}{l}36.9 \\
(18.6) \\
\end{array}$ & $35(30)$ & 0.0001 \\
\hline & $\begin{array}{l}\text { drug } \\
\text { dependence }\end{array}$ & $\begin{array}{l}23.6 \\
(15.8) \\
\end{array}$ & $18(18)$ & $\begin{array}{l}28.3 \\
(16.1)\end{array}$ & $23(17)$ & $\begin{array}{l}35.5 \\
(17.8) \\
\end{array}$ & $32(26)$ & 0.0001 \\
\hline & $\begin{array}{l}\text { post-traumatic } \\
\text { stress }\end{array}$ & $\begin{array}{l}29.6 \\
(24.6)\end{array}$ & $21(48)$ & $\begin{array}{l}35.9 \\
(24)\end{array}$ & $35(46)$ & $\begin{array}{l}40.8 \\
(25.9)\end{array}$ & $44(46)$ & 0.0003 \\
\hline \multirow[t]{3}{*}{$\begin{array}{l}\text { Severe clinical } \\
\text { syndromes }\end{array}$} & $\begin{array}{l}\text { thought } \\
\text { disorder }\end{array}$ & $\begin{array}{l}50 \\
(19.9)\end{array}$ & $55(24)$ & $\begin{array}{l}55.4 \\
(17.5)\end{array}$ & $60(19)$ & $\begin{array}{l}58.7 \\
(14.8)\end{array}$ & $64(19)$ & 0.0003 \\
\hline & $\begin{array}{l}\text { major } \\
\text { depression }\end{array}$ & $\begin{array}{l}36.5 \\
(23.9) \\
\end{array}$ & $35(48)$ & $\begin{array}{l}41.8 \\
(23.2)\end{array}$ & $52(44)$ & $\begin{array}{l}48.3 \\
(22.4)\end{array}$ & $52(31)$ & $<0.001$ \\
\hline & $\begin{array}{l}\text { delusional } \\
\text { disorder }\end{array}$ & $\begin{array}{l}33.7 \\
(19.9)\end{array}$ & $28(36)$ & $\begin{array}{l}40 \\
(20.5)\end{array}$ & $35(39)$ & $\begin{array}{l}45.6 \\
(21.2)\end{array}$ & $47(35)$ & 0.0003 \\
\hline
\end{tabular}


Regarding the multivariate regression analysis, two models were run to determine the predictors of smoking including personality disorders. The first model suggested three factors as the independent predictors of the outcome of being a regular smoker, these included sex and two personality disorders (screened as a score $>75$ in each subgroup). Male sex increased the likelihood of being a regular smoker. Depressive personality increased the likelihood of being a regular smoker by 2.8 times ( $\mathrm{OR}=2.8,95 \%$ CI: $1.3-6.1)$. This factor stayed stable through modeling steps with a p-value below 0.05 in all co-factor combinations. The second personality disorder included in the model was sadistic personality with an odds ratio of 7.9 but a wide confidence interval $(1.2-53 \%)$ and a p-value of 0.03 . The second multivariate logistic regression model assessed the determinants of being a smoker, either experimenter or regular smoker. Male sex increased the likelihood of the outcome, similar with the first model. Among the personality disorders, two of them were kept in model. Histrionic personality increased the likelihood of experiencing smoking by 2.2 times $(\mathrm{OR}=2.2,95 \% \mathrm{CI}$ : 1.6-3.1). This factor stayed stable through modeling steps with a p-value below 0.05 in all co-factor combinations. The second personality disorder included in the model was borderline personality with an odds ratio of 2.8 , a confidence interval of $0.97-8.1 \%$ ) and a borderline P-value of 0.058 . With respect to ever smoking when including both experimenters and regular smokers, depressive personality although associated with ever smoking, lost its significance when introducing histrionic personality variable into the model. There was only a weak correlation between the numeric scales of these two patterns $(\rho=0.35, p<0.05)$ but no interaction was observed between them.

\section{Discussion}

In present study, the authors found that personality patterns were associated with smoking, and behavior of smoking was also different according to the personality pattern. As predictable, it has been suggested that the change in these patterns affects some of the consumption behaviors. A study on student population demonstrated that decreasing neuroticism and impulsivity correlates with decreased substance involvement during emerging adulthood (19). We found that depressive personality increases the likelihood of regular smoking by 2.8 times and histrionic personality increases the chance of smoking, either as an experimenter or as a regular smoker, by 2.2 times. Although evidence is not very solid, few studies have consistently reached the association between smoking patterns and histrionic personality feature $(7,20-22)$. Excessive attention-seeking emotions are characteristic for histrionic personality although being a known feature of ADHD too. Attention seeking behavior is more plausible for being an experimenter rather than a regular smoker. Such behavior may be more likely to happen for teenagers in their communication circles. ADHD and personality features associated with behavioral dyscontrol and novelty seeking have the plausibility of smoking experience as well as other similar risk taking behavior such as substance abuse or risky motorcycle riding behavior among youths $(5,6,23,24)$. Sociability predicts nicotine dependence in men, but in the women's group no personality scale emerged as a significant predictor of nicotine dependence (25). It has been shown that higher levels of openness to experience and neuroticism could be related to higher risk of any lifetime cigarette use (22). A study in Turkey compared 75 cigarette smokers with 77 nonsmokers concluding that partial, but weak, support exists to the notion that smokers are more likely to present with personality features associated with behavioral dyscontrol and novelty seeking (26). However, statistical power should be considered as a major limitation on their findings, taking into account the extent of comparisons that may even affect larger studies such as ours with 1000 samples. A recent meta-analysis of nine cohort studies showed that adult smokers have higher extraversion, higher neuroticism and lower conscientiousness personality scores than non-smokers (27). Ever-smoking in present study also had a most probable association with borderline personality. In line with our findings, borderline personality disorder is stated to be associated with smoking or smoking continuation (28). Other studies have also considered relationship between borderline personality and smoking or substance use (29). Those in the borderline personality disorder are prone to significant emotional instability that may be considered as an explanation for the chance to experiment in smoking. Depressive personality in present study was significantly associated with ever-smoking at starting to develop the multivariate model, but it lost its significance introducing histrionic personality variable into the model. Depression as a mood disorder is considered as a known associate of smoking, regardless of the direction for potential causality relationships, however, the association between depressive mood and smoking is not well documented in literature (30-34). An interventional study on smoking cessation showed that those scoring high at depressive, borderline, sadistic, negativistic, masochistic and schizotypal personality patterns contrary to compulsive personality were less likely to quit smoking (10). Histrionic, depressive and narcissistic were respectively the most common personality patterns both among the girls and boys and no difference was evident between boys and girls in this pattern, however, gender was a significant predictor of smoking in present study. When assessing the personality patterns of smokers seeking smoking cessation treatment in a previous study, it was shown that women scored higher in the histrionic and compulsive patterns, whilst in men, the narcissistic pattern is the most prevalent (10). In our study, not only the prevalence of ever-smoking was lower 
among the girls, but also their pattern of smoking was also different such that $99 \%$ of the 77 girl ever-smokers were experimenters with just one girl being a regular smoker, while $70 \%$ of the 131 ever-smoked boys were experimenters and 30\% were regular smokers. There may be different reasons for smoking in males and females such as women smoke more for tension reduction and relaxation as well as stimulation and social reasons than do the men (35). It is quite common for the male gender to have higher prevalence of smoking in many countries as well as Iran, however, recent studies have focused on the effect of either gender on smoking cessation programs (3638). Sex may also be an important factor in impulsive decision-making and time perception crucial during abstinence (39).

\section{Limitations and recommendations for future research}

In investigation of potential causal relationships between personality disorders and smoking or substance use, the common factors affecting both, such as genetic factors, should always be considered. As an example, for regular smoking and for-ever use of cannabis, the correlation with borderline personality traits has been explained by common genetic factors (29). The cross-sectional nature of the study design may lead to selective survival bias and hinder drawing causal relationships. The instrument used for the assessment of personality patterns, the MCMI-III, is a widely used tool which is based on a specific theoretical perspective. However, it has limitations in its limited most appropriate target groups, and current critics on its usefulness. This may also affect findings of the present study. Having taken into account these limitations, we preferred to draw rather conservative conclusions. The authors' recommendation for future research could be to consider confirming the tool validity through psychiatric interviews. Moreover, with respect to common mechanisms explaining smoking behavior among ADHD, mood disorders, histrionic and depressive personality disorders, future cohort studies through joint assessment of all these disorders, preferably though psychiatric interviews, is strongly recommended.

\section{Conclusions}

Histrionic and depressive personalities could be considered as strong associates of smoking followed by borderline and sadistic personalities. A causal relationship couldn't be assumed unless well controlled longitudinal studies reach the same findings using psychiatric interviews. Knowing about the patterns mapped out in this study could be of help for mental health specialists and policy makers in the screening and development of mental health promotion plans with respect to smoking. In this study the aim was not to define personality disorders, the aim was merely to describe the patterns as an exploratory study, so we strongly recommend conduct of confirmatory studies while taking advantage of full psychiatric examinations.

\section{Acknowledgments:}

The authors cordially thank the staff in the Research Center of Psychiatry and Behavioral Sciences who helped in conducting this study. The authors are thankful to Tabriz University of Medical Sciences for financially supporting the project. This article is based on a thesis project for degree of specialty in psychiatry at Tabriz University of Medical Sciences.

\section{Conflict of Interest:}

There is no conflict of interest to be declared.

\section{Authors' contributions:}

All authors contributed to this project and article equally. All authors read and approved the final manuscript.

\section{References:}

1) Ezzati M, Lopez AD. Estimates of global mortality attributable to smoking in 2000. Lancet. 2003; 362(9387): 847-52. doi: 10.1016/S0140-6736(03)14338-3. PMID: 13678970.

2) Ezzati M, Lopez AD, Rodgers A, Vander Hoorn S, Murray CJ. Selected major risk factors and global and regional burden of disease. Lancet. 2002; 360: 1347-60. doi: 10.1016/S0140-6736(02)11403-6. PMID: 12423980.

3) Abdullah AS, Husten CG. Promotion of smoking cessation in developing countries: a framework for urgent public health interventions. Thorax. 2004; 59(7): 623-30. PMID: 15223875, PMCID: PMC1747072.

4) Shek DT. Paternal and maternal influences on the psychological well-being, substance abuse, and delinquency of Chinese adolescents experiencing economic disadvantage. J Clin Psychol. 2005; 61(3): 21934. doi: 10.1002/jclp.20057. PMID: 15515041. 
5) Safiri S, Sadeghi-Bazargani H, Amiri Sh, Khanjani N, Safarpour H, Karamzad N, et al. Association between Adult Attention Deficit-Hyperactivity Disorder and motorcycle traffic injuries in Kerman, Iran: a case-control study. Journal of Clinical Research \& Governance. 2013; 2(1): 17-21. doi: 10.13183/jcrg.v2i1.24.

6) Downey KK, Pomerleau CS, Pomerleau OF. Personality differences related to smoking and adult attention deficit hyperactivity disorder. J Subst Abuse. 1996; 8(1): 129-35. doi: 10.1016/S0899-3289(96)90139-X. PMID: 8743773 .

7) Black DW, Zimmerman M, Coryell WH. Cigarette smoking and psychiatric disorder in a community sample. Ann Clin Psychiatry. 1999; 11(3): 129-36. doi: 10.3109/10401239909147061. PMID: 10482122.

8) Brook JS, Zhang C, Balka EB, Seltzer N, Brook DW. Personality characteristics in the mid-forties predict women's smoking cessation in their mid-sixties. Psychol Rep. 2013; 113(3): 921-9. doi: 10.2466/09.10.13.PR0.113x26z9. PMID: 24693821, PMCID: PMC3979540.

9) Leventhal AM, Japuntich SJ, Piper ME, Jorenby DE, Schlam TR, Baker TB. Isolating the role of psychological dysfunction in smoking cessation: relations of personality and psychopathology to attaining cessation milestones. Psychol Addict Behav. 2012; 26(4): 838-49. doi: 10.1037/a0028449. PMID: 22642858 , PMCID: PMC3445746.

10) Piñeiro B, López-Durán A, Fernández Del Río E, Martínez U, Becoña E. Gender differences in personality patterns and smoking status after a smoking cessation treatment. BMC Public Health. 2013; 13: 306. doi: 10.1186/1471-2458-13-306. PMID: 23565918, PMCID: PMC3626676.

11) Piñeiro B, Fernández Del Río E, López-Durán A, Martínez U, Becoña E. The association between probable personality disorders and smoking cessation and maintenance. Addict Behav. 2013; 38(8): 2369-73. doi: 10.1016/j.addbeh.2013.03.017. PMID: 23628430.

12) Fernández Del Río E, López-Durán A, Martínez Ú, Becoña E. Personality disorders and smoking in Spanish general and clinical population. Psicothema. 2016; 28(3): 278-83. doi: 10.7334/psicothema2015.292. PMID: 27448261.

13) Distel MA, Trull TJ, de Moor MM, Vink JM, Geels LM, van Beek JH, et al. Borderline personality traits and substance use: genetic factors underlie the association with smoking and ever use of cannabis, but not with high alcohol consumption. J Pers Disord. 2012; 26(6): 867-79. doi: 10.1521/pedi.2012.26.6.867. PMID: 23281672, PMCID: PMC3744119.

14) Cai Y, Li R, Zhu J, Na L, He Y, Redmon P, et al. Personality, perceived environment, and behavior systems related to future smoking intentions among youths: an application of problem-behavior theory in Shanghai, China. PLoS One. 2015; 10(3): e0122276. doi: 10.1371/journal.pone.0122276.

15) Millon T, Millon C, Davis R, Grossman S. Millon Clinical Multiaxial Inventory (MCMI-III). Minneapolis: Pearson; 1997.

16) Sharifi A, Molavi H, Namdari K. Diagnostic validity of Millon Clinical Multiaxial Inventory-III (Persian version). Knowledge and Research in Psychology. 2006; 34: 38.

17) Littlefield AK, Sher KJ. Smoking desistance and personality change in emerging and young adulthood. Nicotine Tob Res. 2012; 14(3): 338-42. doi: 10.1093/ntr/ntr219. PMID: 22241829, PMCID: PMC3281241.

18) Lang UE, Hellweg R. (Prevalence and role of psychiatric disorders in disability). Versicherungsmedizin 2006; 58: 164-9. PMID: 17212298.

19) Fernandez Del RE, Becona IE. (Personality disorders in smokers: a review). Adicciones. 2010; 22 : $155-72$. PMID: 20549151.

20) Zvolensky MJ, Taha F, Bono A, Goodwin RD. Big five personality factors and cigarette smoking: a 10year study among US adults. J Psychiatr Res. 2015; 63: 91-6. doi: 10.1016/j.jpsychires.2015.02.008. PMID: 25799395.

21) Sousa NO, Grevet EH, Salgado CA, Silva KL, Victor MM, Karam RG, et al. Smoking and ADHD: an evaluation of self medication and behavioral disinhibition models based on comorbidity and personality patterns. J Psychiatr Res. 2011; 45: 829-34. doi: 10.1016/j.jpsychires.2010.10.012. PMID: 21092985.

22) Dinn WM, Aycicegi A, Harris CL. Cigarette smoking in a student sample: neurocognitive and clinical correlates. Addict Behav. 2004; 29(1): 107-26. PMID: 14667424.

23) Nieva G, Valero S, Bruguera E, Andion O, Trasovares MV, Gual A, et al. The alternative five-factor model of personality, nicotine dependence and relapse after treatment for smoking cessation. Addict Behav. 2011; 36(10): 965-71. doi: 10.1016/j.addbeh.2011.05.008. PMID: 21704460.

24) Aycicegi-Dinn A, Sisman S, Dinn WM. Cigarette Smoking and Personality Features. Procedia-Social and Behavioral Sciences. 2014; 159: 232-4. doi: 10.1016/j.sbspro.2014.12.363. 
25) Hakulinen C, Hintsanen M, Munafo MR, Virtanen M, Kivimaki M, Batty GD, et al. Personality and smoking: individual-participant meta-analysis of 9 cohort studies. Addiction. 2015; 110(11): 1844-52. doi: 10.1111/add.13079. PMID: 26227786, PMCID: PMC4609271.

26) Keuroghlian AS, Frankenburg FR, Zanarini MC. The relationship of chronic medical illnesses, poor healthrelated lifestyle choices, and health care utilization to recovery status in borderline patients over a decade of prospective follow-up. J Psychiatr Res. 2013; 47(10): 1499-506. doi: 10.1016/j.jpsychires.2013.06.012. PMID: 23856083, PMCID: PMC3884821.

27) Distel MA, Trull TJ, de Moor MM, Vink JM, Geels LM, van Beek JH, et al. Borderline personality traits and substance use: genetic factors underlie the association with smoking and ever use of cannabis, but not with high alcohol consumption. J Pers Disord. 2012; 26(6): 867-79. doi: 10.1521/pedi.2012.26.6.867. PMID: 23281672, PMCID: PMC3744119.

28) Ho SY, Alnashri N, Rohde D, Murphy P, Doyle F. Systematic review and meta-analysis of the impact of depression on subsequent smoking cessation in patients with chronic respiratory conditions. Gen Hosp Psychiatry. 2015; 37(5): 399-407. doi: 10.1016/j.genhosppsych.2015.05.002. PMID: 26022383.

29) Khan M, Monaghan M, Klein N, Ruiz G, John AS. Associations among Depression Symptoms with Alcohol and Smoking Tobacco Use in Adult Patients with Congenital Heart Disease. Congenit Heart Dis. 2015; 10(5): E243-9. doi:10.1111/chd.12282. PMID: 26108339.

30) Reis TC, Silva RR, Pena GG, Domingos PL, Pereira CS, Farias LC, et al. Sex, age and smoking, but not genetic variation in LEPR (rs1137101), are associated with depressive symptoms. Psychiatr Genet. 2015; 25(3): 137-8. doi: 10.1097/YPG.0000000000000080. PMID: 25714446.

31) Zvolensky MJ, Bakhshaie J, Sheffer C, Perez A, Goodwin RD. Major depressive disorder and smoking relapse among adults in the United States: a 10-year, prospective investigation. Psychiatry Res. 2015; 226(1): 73-7. doi:10.1016/j.psychres.2014.11.064. PMID: 25650047, PMCID: PMC4448723.

32) Eory A, Rozsa S, Gonda X, Dome P, Torzsa P, Simavorian T, et al. The association of affective temperaments with smoking initiation and maintenance in adult primary care patients. J Affect Disord. 2015; 172: 397-402. doi: 10.1016/j.jad.2014.10.036. PMID: 25451443.

33) Berlin I, Singleton EG, Pedarriosse AM, Lancrenon S, Rames A, Aubin HJ, et al. The Modified Reasons for Smoking Scale: factorial structure, gender effects and relationship with nicotine dependence and smoking cessation in French smokers. Addiction. 2003; 98(11): 1575-83. PMID: 14616184.

34) Smith PH, Kasza KA, Hyland A, Fong GT, Borland R, Brady K, et al. Gender differences in medication use and cigarette smoking cessation: results from the International Tobacco Control Four Country Survey. Nicotine Tob Res. 2015; 17(4): 463-72. doi: 10.1093/ntr/ntu212. PMID: 25762757, PMCID: PMC4402353.

35) Gorelick DA. Sex difference in response to varenicline for smoking cessation. Am J Psychiatry. 2015; 172(4): 394-5. doi: 10.1176/appi.ajp.2015.14111429. PMID: 25827037.

36) Mayer D, Simetin IP, Rodin U, Benjak T, Puntaric E, Puntaric I. The impacts of media messaging and age and sex variance on adolescent smoking habits in Croatia. J Addict Med. 2015; 9(2): 147-54. doi: 10.1097/ADM.0000000000000070. PMID: 25807453.

37) Ashare RL, Kable JW. Sex differences in time perception during smoking abstinence. Nicotine Tob Res. 2015; 17(4): 449-54. doi: 10.1093/ntr/ntu260. PMID: 25762755, PMCID: PMC4432399. 